\title{
Chemical, biological and evolutionary aspects of beetle bioluminescence
}

\author{
Etelvino J. H. Bechara*a ${ }^{\text {a }}$, Cleide Costa ${ }^{b}$, Pio Colepicolo ${ }^{a}$, Vadim Viviani, \\ Marcelo P. Barros ${ }^{d}$, Graham S. Timmins ${ }^{\mathrm{e}}$, Abner B. Lall ${ }^{\mathrm{f}}$, Walter R. Terra ${ }^{\mathrm{a}}$, \\ Clélia Ferreira $^{a}$, Cassius V. Stevani ${ }^{\mathrm{a}}$, and Moacir A. Torres ${ }^{\text {ad }}$
}

${ }^{a}$ Instituto de Química, Universidade de São Paulo, SP, Brazil; ${ }^{b}$ Museu de Zoologia, Universidade de São Paulo, SP, Brazil; ' Departamento de Biologia, Universidade Federal de São Carlos, Sorocaba, SP, Brazil; ' Centro de Ciências Biológicas e da Saúde, Universidade

Cruzeiro do Sul, São Paulo, SP, Brazil; ${ }^{e}$ School of Medicine, University of New Mexico, Albuquerque, NM, USA, ${ }^{f}$ Department of Biology, Howard University, Washington D.C., USA E-mail: ebechara@iq.usp.br

This work is dedicated to Prof. Waldemar Adam, an esteemed friend and eminent scientist who, for decades, generously shared knowledge, enthusiasm, and laboratory supplies with many Brazilian investigators, among them G. Cilento and myself. In 1980, Prof. Adam was elected Foreign Member of the Brazilian Academy of Sciences in recognition for his substantial contributions towards the development of Chemistry in Brazil.

\begin{abstract}
The hypothesis that luciferases evolved from ligases that acquired oxygenase and luminogenic activities, thereby contributing to the antioxidant machinery of bioluminescent organisms, is revisited here. Larvae of click beetle Pyrearinus termitilluminans (Coleoptera: Elateridae) live under conditions close to normoxia into tunnels dug into termite mounds, whereas other elaterid larvae inhabit tunnels in decaying logs, where $\mathrm{pO}_{2}$ is $\sim 2-5 \%$. Interestingly, the catalase and superoxide dismutase (SOD) activities in click beetle larvae were found to respond to the habitat $p \mathrm{O}_{2}$ and are significantly lower in non-luminescent elaterids. Exposure of larval $P$. termitilluminans larvae to hyperoxia induced SOD and catalase activities concomitantly with increments in luciferase and luciferin levels mainly in the prothorax, the brightest larval segment. Thoracic luciferase activity is 1000 -fold higher than in the abdomen, while SOD activity is 2fold higher. With larval development, an expected decline in antioxidant enzyme activities was apparently compensated by an increase in luciferase activity (2-3 fold) and in urate (40-fold), a major insect antioxidant. Finally, we found that the ligase-rich fat body of larval Tenebrio molitor, a non-luminescent beetle, contains a primal luciferase-like activity. Altogether, these data strengthen the hypothesis that various bioluminescent systems may have developed from potentially chemiluminescent metabolites and ligases that acquired a dioxygenase and luminogenic function over the course of evolution.
\end{abstract}


Keywords: Bioluminescence, luciferase, firefly, oxidative stress, superoxide dismutase, ligase

\section{Introduction}

Emission of visible and "cold" light by living organisms is called bioluminescence. It occurs mainly in deep-sea marine organisms and less frequently on land and serves as a means of intraspecies and inter-species communication, as in mating, predation, defense, warning, congregation and territoriality. Bioluminescent species include bacteria, fungi, dinoflagellates, coelenterates, mollusks, annelids, crustaceans, insects, hemichordates, echinoderms, and chordates. Bioluminescence usually results from the oxidation of a substrate, called luciferin, by molecular oxygen, in the presence of an enzyme, named luciferase, yielding the product oxyluciferin - in the fluorescent state, the reaction emitter. ${ }^{1}$ The quantum yield of bioluminescence can be as high as $88 \%$ in fireflies or $28 \%$ in the ostracod Cypridina. Bioluminescent colors range from blue to red and are affected not only by the luciferin and luciferase structures but also, in some cases, by inner biological filters and accessory lumiphores. Because the firefly light reaction is stoichiometrically dependent on ATP as a luciferin activator, it is very useful for determining metabolites and enzymes participating in ATP-dependent reactions. ${ }^{1,2}$ Currently, with very sensitive photocounters and luminometers, ATP can be easily detected at pico or femtomolar concentrations in biological fluids and microorganismcontaminated food, medicines, treated water, hospital specimens, and other materials. Furthermore, cloned luciferase reporters play major roles in modern studies of gene expression. ${ }^{3}$

In the Insecta, the Coleoptera lodges the largest number of luminescent species, which are distributed among three main families: Lampyridae (fireflies), Elateridae (click-beetles, fire beetles) and Phengodidae (railroad worms), the latter exhibiting extraordinary sexual dimorphism: females are apteral, larviform, and males, winged. ${ }^{4}$ Lampyridae and Elateridae are very diverse groups abundant all over the world, and Phengodidae are distributed throughout the New World from extreme southern Canada to Chile including the Nearctic and Neotropical biogeographical regions. ${ }^{5}$ The occurrence of luminescent beetles in Brazil was first reported in 1587 by the Portuguese traveler Gabriel de Souza, who described clouds of fireflies inhabiting the forests and meadows, named mamoás by Amerindian natives and cagalumes or lucernas by the Portuguese colonizers, and "strange creatures" like caterpillars crowned with rubis (probably, phengodids), named buijejas by the Amerindian natives. ${ }^{6}$

Adult lampyrids flash green-yellow light from abdominal ventral lanterns during their nuptial flight and on the grass while mating. Adult elaterids continuously shine green light from a pair of thoracic dorsal lanterns when flying or walking on vegetation and yellow-orange light from an abdominal ventral lantern when flying. Adult male phengodids light emission ranges from green to yellow, but some species emit orange and reddish light. Their lanterns are located dorsolaterally along the abdominal and thoracic segments, the prothoracic segment having a 
dorsomedian light organ. In some phengodid species there is a very small lantern frontally on the head between the eyes. Larviform female and phengodid larvae display cephalic lanterns whose colors range from green (Phengodes latticolis) to red (Phrixothrix vivianii), depending on the species, and several pairs of laterally located green (Phengodes latticolis) to orange (Mastinomorphus spp) lanterns in the abdomen (Table 1). ${ }^{4,7-9}$

Table 1. Colors of beetle bioluminescence ${ }^{\mathrm{a}}$

\begin{tabular}{|c|c|c|c|}
\hline Families & Phase & Lantern & Bioluminescence Peak (range) \\
\hline Lampyrid & adult and larva & $\begin{array}{l}\text { abdominal } \\
\text { ventrites }\end{array}$ & 547 - 584 nm (green - yellow) \\
\hline \multirow{4}{*}{ Elaterid } & \multirow{3}{*}{ adult } & $\begin{array}{l}\text { pronotum } \\
\text { (dorsal) }\end{array}$ & 536 - 559 nm (green - yellow) \\
\hline & & first & \\
\hline & & $\begin{array}{l}\text { sternite } \\
\text { (ventral) }\end{array}$ & 549 - 594 nm (green - orange) \\
\hline & larva & prothorax & $\begin{array}{c}530-560 \mathrm{~nm}(\text { green - } \\
\text { yellow/green })\end{array}$ \\
\hline \multirow{3}{*}{ Phengodid } & \multirow[t]{2}{*}{ adult male } & $\begin{array}{l}\text { abdominal } \\
\text { tergites }\end{array}$ & \multirow[b]{2}{*}{$562-638 \mathrm{~nm}$ (yellow-green - red) } \\
\hline & & head & \\
\hline & larva and adult female & $\begin{array}{c}\text { abdominal } \\
\text { tergites } \\
\text { (lateral) }\end{array}$ & 535-592 nm (green - orange) \\
\hline
\end{tabular}

${ }^{a}$ Data collected from Biggley, Lloyd, Colepicolo Neto et al., and Viviani and Bechara. ${ }^{4,7}$

Beetle luciferin, a benzothiazole compound biosynthesized from cysteine, is identical in all three families. ${ }^{8,10}$ The luciferase first acts as a synthetase, catalyzing luciferin activation by adenylation at the expense of ATP. Subsequently, it behaves as a dioxygenase promoting molecular oxygen insertion into the luciferin-AMP intermediate, followed by its cyclization to an "energy-rich" dioxetanone intermediate. An electron exchange pathway between the dioxetanone moiety and the conjugated thiazole-benzothiazolic ring, known as CIEEL (Chemically Initiated Electron Exchange Luminescence), ${ }^{11}$ is currently considered the best mechanistic explanation to account for carbon dioxide and excited singlet oxyluciferin formation, which decays to the ground state by light emission (Scheme 1).

Two hypotheses have been proposed to explain the distinct colors obtained from beetle luciferases: one is based on a tautomeric equilibrium of the nascent excited oxyciferin at the enzyme active site, where the oxyluciferin enolate form emits yellow-green light and the keto form emits red (Scheme 1), ${ }^{12,13}$ and the second suggesting that yellow-green or red color are 
elicited, respectively, by coplanar or perpendicular rotamers of excited oxyluciferin along the 2,2'-axis binding the thiazole to the benzothiazole ring. ${ }^{14}$ According to Orlova et al. the participation of the enol forms of oxyluciferin is plausible but not required to explain the multicolor emission of beetle bioluminescence. ${ }^{15}$ In addition, a theoretical examination of the firefly light reaction led them to support the generally accepted CIEEL theory long proposed by McCapra and Schuster and co-workers. ${ }^{16,17}$

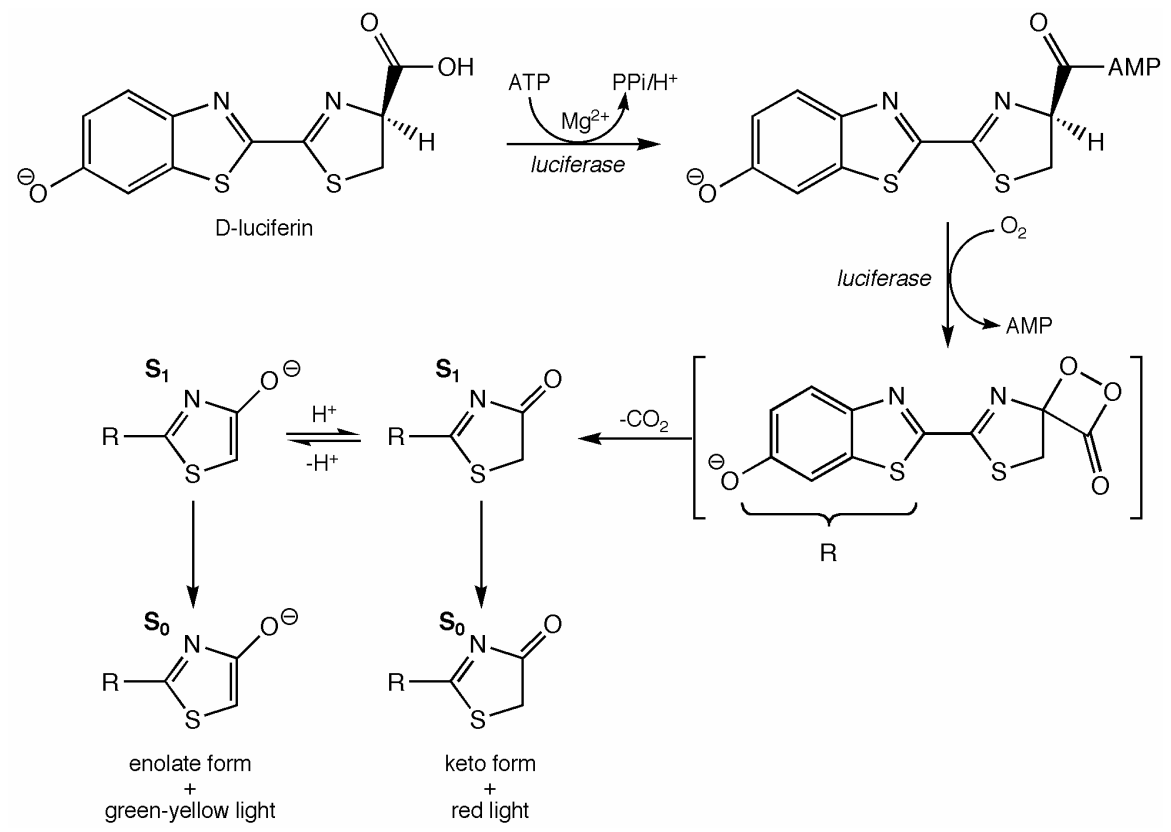

Scheme 1. Reaction pathway for firefly bioluminescence leading to red-emitting keto oxyluciferin and/or yellow-green-emitting enol oxyluciferin. $\mathrm{S}_{0}$ and $\mathrm{S}_{1}$ stand for ground state and excited singlet state, respectively.

Participation of dioxetane and dioxetanone intermediates in chemi- and bioluminescent reactions had been hypothesized since the XIX century according to Kopecky, ${ }^{18}$ but gained credibility only after the publication of the synthesis and chemiluminescent characterization of the 3,3,4-trimethyl-1,2-dioxetane by Kopecky and Mumford in 1969 and of the 3,3-dimethyl-1,2dioxetanone by Adam and Liu in 1972 (Scheme 2). ${ }^{19,20}$ The thermolysis of both peroxides was shown to produce acetone preferentially in the phosphorescent, triplet state. Nevertheless intermolecular CIEEL processes of dioxetanones with low oxidation potential fluorescers could afford fluorescent products and thus fit plausible models for high efficient chemi- and bioluminescent reactions. 


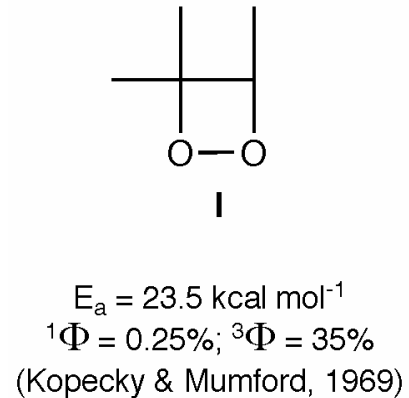

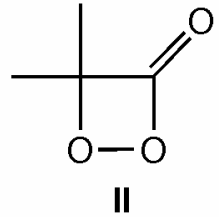

$E_{\mathrm{a}}=19.8 \mathrm{kcal} \mathrm{mol}^{-1}$

${ }^{1} \Phi=0.1 \%{ }^{3} \Phi=1.5 \%$

(Adam \& Liu, 1972)

Scheme 2. First synthesized dioxetaneError! Bookmark not defined. and dioxetanone ${ }^{20}$ : (I) 3,3,4-trimethyl-1,2-dioxetane and (II) 3,3-dimethyl-1,2-dioxetanone. $\mathrm{E}_{\mathrm{a}}$, activation energy of thermolysis; ${ }^{1} \Phi$, quantum yield of singlet product; ${ }^{3} \Phi$, quantum yield of triplet product.

\section{Brazilian luminous termite mounds}

The biodiversity of bioluminescent coleoptera in Brazil is very impressive, comprising $1.3 \%$ of all the elaterid species described in the literature, $17 \%$ of the lampyrids, and $24 \%$ of the phengodids. $^{21,22}$ The cerrados of central Brazil surprise their visitors with one of the most magnificent scenes of bioluminescence on the planet - the "luminous termite mounds", just as spectacular as the luminous Waitomo caves in New Zealand (attributed to the diptera Arachnocampa luminosa), the "phosphorescence bay" of San Juan de Puerto Rico illuminated by myriads of luminous dinoflagellates, and the shoals of flash-light fishes (Photoblepharon steinitz) in the Red Sea. During the rainy season, just after sunset, hundreds of termite mounds begin to illuminate the fields with tiny luminous green spots distributed on the surface of the mounds (100-400 lights/mound), resembling Christmas trees. ${ }^{23}$ The light comes from larvae of the clickbeetle Pyrearinus termitilluminans (Coleoptera: Elateridae) housed in the mounds. ${ }^{24}$ These larvae excavate an intricate network of tunnels in the outer layers of the mounds, with exits to the outside, where they expose their head and green-shining thorax to attract and catch flying prey, specially termites and ants. The profusion of flying prey attracts other commensals to the banquet, including spiders, scorpions, frogs and millipedes, which in turn attract birds, whose seed-containing excrements nucleate a variety of vegetation around the mound.

Elaterid larvae can be found in very distinct biotypes in the soil, litter, termite nests and rotted wood. They can be saprophages, phytophages, or predators, but all possess extra oral digestion. Their mouthpart present a maxillolabial complex densely clothed with short hairs at its internal surface forming a kind of an oral filter that keep solid particles out of the gut; that characteristic is associated with liquid feeding. ${ }^{25}$ This is also the case of Pyrophorus divergens, collected from decaying logs, and Pyrearinus termitilluminans, gathered in the termite mounds. ${ }^{26-28}$ Elaterid larvae regurgitate a dark liquid when biting their prey or the collector's fingers if handled. The regurgitate contains trypsin and a mixture of carbohydrases (amylase, cellulase, trehalase, and $\alpha$ - and $\beta$-glucosidase), which accomplishes initial, extra-corporeal digestion of the prey. Preliquefied material is then ingested by the larvae, and the intermediate and final digestion take place on the surface of the midgut cells, carried out by aminopeptidase, 
$\alpha$-glucosidase, and trehalase. The $\mathrm{pH}$ optima of the digestive enzymes range from 6 and 8.5, which agrees with the $\mathrm{pH}$ value of the regurgitate and midgut contents. The physical-chemical properties $\left(\mathrm{K}_{\mathrm{M}}, \mathrm{pI}, \mathrm{MW}\right)$ of the digestive enzymes found in the regurgitates of larval bioluminescent elaterids revealed that they are functionally identical. Redford, ${ }^{29}$ when describing the bioluminescence associated with the termite mounds stated that it "is clearly an evolutionary response by $P$. termitilluminans larvae to a short, very rich probe of food - the myriad social insects, released during alate flights." It is thus tempting to suggest that Pyrearinus evolved from a vegetarian ancestor, therefore accounting for the cellulase and high $\beta$-glucosidase activities found in their digestive tract.

\section{Does bioluminescence cooperate with anti-oxidant enzymes in redox balance?}

In flashing fireflies or continuously shining click beetles and railroad worms, the oxygenconsuming bioluminescent pathway is expected to compete for a fraction of the inhaled oxygen with respiring mitochondria and other metabolic routes catalyzed by mono- and dioxygenases (Scheme 3). As the oxyluciferin emitter is an excited singlet keto species with very short lifetime and high fluorescence quantum yield, it is not expected to trigger photochemical-like oxidative effects on biomolecules. In contrast, excited triplet carbonyls are long-lived, known to behave chemically as alkoxyl radicals, and therefore able to induce oxidative damage to cell components. $^{30}$

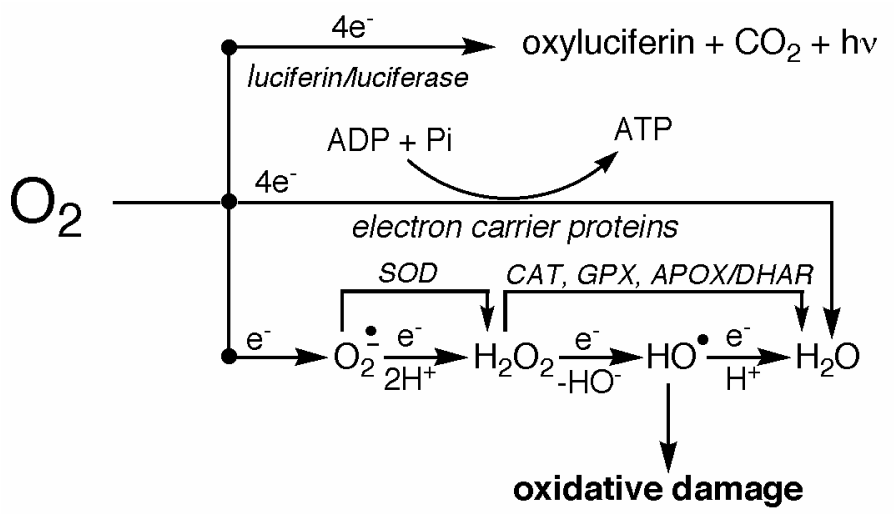

(i) bioluminescence

(ii) mitochondrial respiration

(iii) oxyradical metabolism

Scheme 3. Competitive pathways for oxygen uptake in bioluminescent organisms. SOD, superoxide dismutase; CAT, catalase; GPX, glutathione peroxidase; APOX, ascorbate peroxidase; DHAR, dehydroascorbate reductase.

In an attempt to estimate the fraction of inspired oxygen that is diverted to the light reaction, we ran in vivo EPR oxymetry in dim and shining larval $P$. termitilluminans. ${ }^{31}$ The EPR signal line width due to paramagnetic lithium phthalocyanine implanted in the larva prothorax linearly senses the local $\mathrm{pO}_{2}$. Inside the EPR sample chamber, the larva was prodded with a cotton tip or with a Drosophila prey, causing it to shine, and both $\mathrm{pO}_{2}$ and bioluminescence intensity were recorded over time under external normoxia. A reduction in prothorax $p \mathrm{O}_{2}$ within the range of 
10-25 mmHg was observed, which represents up to $20 \%$ of intracellular oxygen consumed in the light reaction. From in vivo EPR experiments we later concluded that the molecular oxygen diffusion required $\sim 600 \mathrm{~ms}$ in the gas phase and $\sim 1300 \mathrm{~ms}$ in tissue aqueous phase, suggesting that modulation of tracheolar fluid levels is the mechanism that controls tissue oxygen levels in beetles. $^{32}$

Recently, Trimmer et al. ${ }^{33}$ reported that light emission by adult lampyrids (Photuris sp.) can be stimulated by nitric oxide ( ${ }^{\circ} \mathrm{NO}$, a radical molecule) in the presence of oxygen and that ${ }^{\circ} \mathrm{NO}$ scavengers abolish bioluminescence triggered by the neurotransmitter octopamine. These and other data reported by the authors supported the hypothesis that in firefly, flashing control is provided by octopamine-induced release of $\mathrm{NO}$ in terminal tracheoles, diffusion of ${ }^{\circ} \mathrm{NO}$ to mitochondrial photocytes, where the gas binds to and transiently inhibits cytochrome oxidase, leading to a sudden accumulation of oxygen in the peroxisomes where the light reaction takes place. Because white light dissociates the complex NO-cytochrome oxidase of mammalian mitochondrial preparations, it is possible that in the firefly lantern, the flash itself turns off the bioluminescence. However, many questions must yet to be answered regarding this hypothesis, including: How does octopamine activate the NO synthase? Being a highly diffusible gas, does 'NO impair respiration of other cells adjacent to the photocytes? Paradoxical is the fact that by inhibiting the respiratory chain, the synthesis of ATP - a crucial reagent of the bioluminescent reaction - is also impaired.

That bioluminescence may have evolved as an ancient $\mathrm{O}_{2}$ detoxifying mechanism with the sole purpose of $\mathrm{O}_{2}$ consumption was hypothesized by McElroy and Seliger. ${ }^{34}$ Later, Seliger proposed that luciferases arose from mixed-function oxygenases to remove unsaturated compounds during early life history, ${ }^{35}$ and Wood suggested that luciferases did not evolve from oxygenases but rather, that the luminescent phenotypes drove the evolution of new oxygenase functions. ${ }^{36}$ That the bioluminescent reaction may contribute to minimize oxidative stress was indicated by concomitant induction of superoxide dismutase (SOD) and luciferase in luminescent Xenorhabdus luminescens bacteria when subjected to hyperoxia and by reported antioxidant properties of coelenterazine, ${ }^{37}$ the luciferin of several marine organisms, ${ }^{38}$ and of firefly luciferin towards chemical and biological targets. ${ }^{39}$ Recently, Dubuisson et al. reviewed the striking antioxidative properties of coelenterazines and derivatives towards singlet oxygen, peroxynitrite, radical anion superoxide and other radicals, thereby affording protection against oxidative injury promoted, for example, by tert-butyl hydroperoxide to cells and ischemia-reperfusion in hamster. ${ }^{40}$ These authors emphasize the therapeutic potential of synthetic imidazolopyrazinones (coelenterazine analogs).

Our first attempt to demonstrate a possible metabolic interplay between luciferase and SOD took place in the 1980s with larvae of several species of luminescent and non-luminescent elaterids. ${ }^{26,27}$ The levels of SOD - the frontline antioxidant defense of aerobes - were then found to be about 5-fold lower in non-luminescent larval elaterids (Chalcolepidus sp, Ischiodontus sp, Platycrepidus, Conoderus sp) than in larvae of luminescent elaterid Pyrophorus divergens and another Pyrophorini. The SOD activity of larval lampyrids (Bicellonycha sp.) and phengodids 
(unidentified) were also much higher (5-15 times) than in non-luminescent elaterids. ${ }^{41}$ Curiously, the SOD level responds to the $\mathrm{PO}_{2}$ in the habitat: it is 3-fold higher in larval Pyrearinus termitilluminans, which lives in well-aerated tunnels excavated in the termite mounds, than in Pyrearinus candelarius, which dwells in decaying logs where $p \mathrm{O}_{2}$ may drop to less than $5 \%$. Moreover, the brightest segments of $P$. termitilluminans larva - the prothorax and the 9-10 abdominal segments - are 2-fold richer in SOD than its $\operatorname{dim} 1^{\text {st }}-8^{\text {th }}$ abdominal segments. Higher SOD activities in luminescent beetles and in their lanterns were then interpreted as a protective response induced by the superoxide anion radical against oxygen accumulation in the photocytes to sustain the light reaction. Accordingly, photocytes contain a high population of superoxideproducing mitochondria densely located near the nervous and tracheal terminals. In the dry season (April-August), when the temperature and air humidity drop and flying prey is unavailable, Pyrearinus termitilluminans larvae probably depend on the storage of trehalose, a nonreducing glucose disaccharide present in a wide variety of organisms, including bacteria, yeast, fungi, insects, invertebrates, and plants. It is known to act as an antioxidant and antidesiccant, stabilize proteins and membranes, and thereby protect the integrity of cells. ${ }^{42}$ Accordingly, $P$. termitilluminans larvae submitted to dryness conditions in a climatic chamber expressed 80 -fold higher trehalase activity and 10-fold higher glucose concentration as compared to the control group. ${ }^{43}$ Together with glycogen, trehalose was shown to be a crucial metabolic source of energy and water under such dry conditions. Concomitant increases in SOD and catalase activities were also observed, pointing to redox imbalance in larvae subjected to water stress.

In the 1980s we brought into consideration further evidence supporting the notion that bioluminescence may cooperate with the antioxidant chemical and enzymatic machinery of the photocytes to properly balance their redox status. Pyrearinus termitilluminans larvae were collected from luminous termite mounds in open fields near the Emas National Park (GO, Brazil) and raised in our laboratories, where they were challenged with various redox stimuli: hyperoxia, hypoxia, luciferin methyl ether - a firefly luciferase inhibitor, and the juvenile hormone 20hydroxy ecdsysone.

Upon exposure of $P$. termitilluminans larvae to pure oxygen for 72 hours, the prothorax activities of total SOD, mitochondrial SOD and catalase were found to increase by 80,100 , and $50 \%$, respectively. ${ }^{44}$ Concomitantly, the levels of luciferase and luciferin increased 80 and $50 \%$, respectively. Similar enzyme increments were also observed in the abdomen extracts. The luciferase activity was found to be three orders of magnitude higher in prothorax than in abdomen and to peak at 7 p.m., which is the time of day when larvae light up in the laboratory and in their habitat to attract prey. ${ }^{45}$ After 8 p.m., the larvae turn off their lanterns and the luciferase activity drops to basal values. Morning increases in antioxidant enzymatic activities (SOD, catalase) were associated with intense physical activity involved in digging tunnels and/or digesting captured prey. Assays with thiobarbituric acid showed augmented lipid peroxidation in the abdomen, where the levels of antioxidant enzymes and luciferase are low, attesting to exacerbated production of deleterious oxyradicals induced by hyperoxia. Accordingly, decreases 
of thiol proteins and a reduced glutathione/total glutathione ratio were verified in the prothorax, the brightest larval segment. Noteworthy is that, in laboratory, the activity of larval $P$. termitilluminans luciferase peaks at about 19:30 h, when the larva start shining in the termite mounds to attract preys, and SOD levels were found to be maximal at early night and during the morning, when the larvae where observed digging tunnels in the soil substrate where they are raised. ${ }^{45}$ These observations are in agreement with the notion that oxygen-demanding biological activities - light emission and physical exercise in this case - require efficient antioxidant protection. $^{46}$

Exposure of Pyrearinus termitilluminans larvae to hypoxia $\left(2 \% \mathrm{O}_{2}\right.$ for 72 hours $)$ did not change the activities of antioxidant enzymes and of luciferase in larvae, but affected the insects' respiratory activity, as indicated by significant increases in lactate dehydrogenase and Krebs cycle enzymes in the prothorax. ${ }^{44}$ A slight but significant decrease in luciferin was observed. Under normoxia, the antioxidant enzymes were probably expressed to a constitutive level that provides satisfactory protection from normal or lower production of reactive oxygen species.

Injecting luciferin methyl ether, a non-competitive inhibitor of luciferase, into the first abdominal segment of the larvae led to an expected decrease of the luciferase activity in both prothorax and abdomen. ${ }^{44}$ However the drop in luciferase activity was not offset by an increase in SOD or catalase. The luciferase inhibitor did not affect the enzymatic antioxidant defenses but, instead, caused a substantial decrease in reducing thiol protection, indicative of oxidative damage. When the inhibitor-treated larvae were exposed to hyperoxia, induction of protective SOD was observed, although substantial oxidative damage to lipids and proteins was unavoidable.

Insects show unique adaptations to cope with oxidative challenges during larval development, metamorphosis and adulthood. Ample data suggest that both aging and larval development in insects are associated with molecular damage inflicted by reactive oxygen species in lipids, proteins and DNA. When comparing small, medium and large size Pyrearinus larvae living under normoxia, we observed significant decrements in total SOD, mitochondrial SOD and catalase during the larva's growth. ${ }^{47}$ A remarkable 50 -fold increase in urate, a powerful antioxidant, plus 3-fold increased luciferase activity was observed, which was probably responsible for preventing extensive oxidative injury. Corroborating this hypothesis, lower levels of lipid peroxidatin products measured as thiobarturic acid reactive substances (TBARS) and of carbonyl proteins were also found in the larger larvae. An attempt to reproduce these data with an acute treatment with the hormone 20-hydroxyecdysone as a growth inducer revealed only its pro-oxidant activity, as indicated by the levels of TBARS, urate, luciferase and the antioxidant enzymes.

\section{Did luciferases evolve from ligases?}

Taking into consideration that beetle luciferases display high structural identity with plant, animal and microorganism ligases, which is not surprising since the rate-limiting step of both reactions involves the activation of a carboxyl group of the substrate by adenylation, followed by thiolation with Coenzyme $\mathrm{A}$ in the case of ligases (Equations 1 and 2), we decided to test the 
hypothesis that firefly luciferase might have evolved from ligases, using larvae of Tenebrio molitor (Coleoptera: Tenebrionidae), a non-luminous beetle. ${ }^{48}$

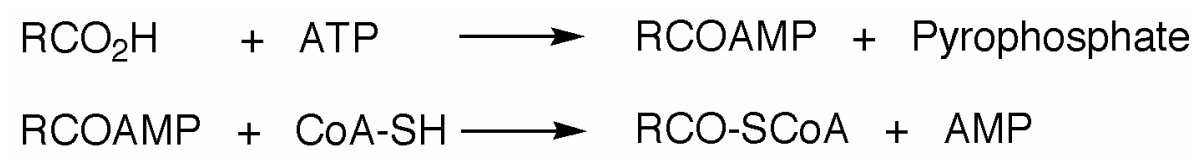

In fireflies, it is currently accepted that reaction 1 is followed by oxygen insertion in the luciferin $\alpha$-carbon forming an $\alpha$-hydroperoxide. Nucleophilic attack of the hydroperoxide group to the carbonyl group displacing AMP is highly favored and would lead to the dioxetanone intermediate, whose cleavage yields the emitter (Scheme 1).

A remarkable finding was the ultra-weak red light emission from larval Tenebrio upon injection of acidified luciferin under the dorsal face of its first abdominal segment. ${ }^{48}$ Extracts were then prepared from ligase-rich body fat of the larvae for an enzymatic characterization of the luciferase-like activity by chemiluminescence measurements, although caution must be taken to interpret molecular events underlying ultra-weak light emissions. The luminogenic Tenebrio enzyme activity showed $\mathrm{K}_{\mathrm{M}}$ values for ATP $(200 \mu \mathrm{M})$ similar to those reported for Photinus pyralis (Lampyridae; $250 \mu \mathrm{M}$ ) and Phrixothrix hirtus (Phengodidae; $360 \mu \mathrm{M}$ ) luciferases. We also found lower affinity for the luciferin $\left(\mathrm{K}_{\mathrm{M}}=800 \mu \mathrm{M}\right.$ in Tenebrio versus 20 and $180 \mu \mathrm{M}$, respectively, in Photinus and Phrixothrix), optimum $\mathrm{pH}$ close to 8.0 like in Photinus (7.9) and Phrixothrix (8.2), and luminescence peaking in the same red region $\left(\lambda_{\max }=610 \mathrm{~nm}\right)$ as the cephalic phengodid lantern. Like Photinus luciferase, the Tenebrio enzyme could be inhibited by AMP, phosphate, pyrophosphate, and luciferin methyl ether. These data underpin the hypothesis that ligases are ancestral luciferases selected during the species evolution primarily to provide ancillary antioxidant protection, together with SOD, catalase, and glutathione peroxidase (See Scheme 3), but endowed with luminogenic activity secondarily adapted for mating and predation.

\section{Final remarks}

In conclusion, the concomitant induction of luciferin and luciferase activity with antioxidant defenses (SOD, catalase, urate, glutathione) during oxidative challenges imposed on bioluminescent elaterid larvae (Pyrearinus termitilluminans) is congruent with the hypothesis that bioluminescent systems cooperate with anti-oxidant enzymes to minimize the deleterious effects of reactive oxygen species. ${ }^{44,45,47}$ Furthermore, the presence of a pro-luciferase activity in a non-luminescent beetle (Tenebrio molitor) strengthens the notion that bioluminescence may have evolved from potentially chemiluminescent metabolites with anti-oxidant properties ${ }^{38}$ and ancestral acylCoA ligases that acquired a dioxygenase and luminogenic function. ${ }^{48}$ The ligase origin, diversity, and structural relationships of beetle and fly (Mycetophilidae) luciferases, recently reviewed by Viviani, ${ }^{49}$ also support this hypothesis. In this context, according to Timmins et al., ${ }^{50}$ a major difficulty in explaining the evolution of bioluminescence as a signaling mechanism is to understand how progressive evolution acted upon primal and low-efficiency 
bioluminescent reactions to select for and optimize a weak exergonic light emission reaction to a threshold sufficiently high to be perceived by light-sensing organs. Indeed, that bioluminescence can be seen by sexual partners during attraction and courtship was demonstrated in the clickbeetle Pyrophorus punctatissimus by the almost perfect spectral match observed between the bioluminescence and the visual spectral sensitivity measured by electroretinography. ${ }^{51}$

\section{Acknowledgements}

This work was financed by grants from the Fundação de Amparo à Pesquisa do Estado de São Paulo (FAPESP), the Conselho Nacional de Desenvolvimento Científico e Tecnológico (CNPq), and the Projeto do Milênio "Redoxoma".

\section{References}

1. Hastings, J. W.; Johnson, C. H. Meth. Enzymol. 2003, 360, 75.

2. Roda, A.; Pasini, P.; Mirasoli, M.; Michelini, E.; Guardigli, M. Trends Biotechonol. 2004, 22, 295.

3. Branchini, B. R.; Southworth, T. L.; Khattak, N. F.; Michelini, E.; Roda, A. Anal. Biochem. 2005, 345, 140.

4. Lloyd, J. E. In Bioluminescence in Action; Herring, P. J., Ed.; Academic Press: 1978, p. 241.

5. Costa, C.; Zaragoza, S. In Handbook of Zoology; Beutel, R. G., Leschen. R. A. B., Eds.; Vol. 4; Friedrich-Schiller-Universität Press, Jena, in press.

6. Moraes, R. B. Noticia do Brasil. Biblioteca Histórica Brasileira, Vol. 16, Pt. 2; Livraria Martins Editora, 1940.

7. Biggley, W. H.; Lloyd, J. E.; Seliger, H. H. J. Gen. Physiol. 1967, 50, 1681.

8. Colepicolo Neto, P.; Pagni, D.; Bechara, E. J. H. Comp. Biochem. Physiol. 1988, 91B, 143.

9. Viviani, V. R.; Bechara, E. J. H. Ann. Entomol. Soc. Am. 1997, 90, 389.

10. Viviani, V. R.; Bechara, E. J. H. Photochem. Photobiol. 1993, $58,615$.

11. Schuster, G. B. Acc. Chem. Res. 1979, 12, 366.

12. White, E. H.; Roswell, D. F. Photochem. Photobiol. 1991, 53, 131.

13. Viviani, V. R.; Bechara, E.J.H. Photochem. Photobiol. 1995, 62, 490.

14. Branchini, B. R.; Southworth, T. L.; Murtiasshaw, M. H.; Magyar, R. A.; Gonzalez, S. A.; Ruggiero, M. C.; Stroh, J. G. Biochemistry 2004, 43, 7255.

15. Orlova, G.; Goddard, J. D.; Brovko, L.Y. J. Am. Chem. Soc. 2003, 125, 6962.

16. McCapra, F. J. Chem. Soc., Chem. Commun. 1977, 946.

17. Koo, J. -K; Schmidt, S. P.; Schuster, G. B. Proc. Natl. Acad. Sci. U.S.A. 1978, 75, 30.

18. Kopecky, K. R. In Chemical and Biological Generation of Excited States; Adam, W.; Cilento, G., Eds. Academic Press: New York, 1982; p 85.

19. Kopecky, K. R.; Mumford, C. Can. J. Chem. 1969, 47, 709. 
20. Adam, W.; Liu, J.-C. J. Am. Chem. Soc. 1972, 94, 2894.

21. Costa, C. In Biodiversidade do Estado de Sao Paulo, Brasil; Brandão, C. R.; Cancello, E. M., Eds; FAPESP: 1999; p. 115.

22. Costa C. In Proyecto CYTED para el Inventario y Estimación de la Diversidad Entomológica en Iberoamérica; Martín-Piera, F.; Morrone, J. J.; Melic, A., Eds; PrIBES 2000, p. 99.

23. Bechara, E. J. H. In Advances in Oxygenated Processes; Baumstark, A. L., Ed.; JAI Press Inc. 1988, p 123.

24. Costa, C. Revta Bras. Zool. São Paulo 1982, 1, 23.

25. Lawrence, J. F. In Immature Insects, Vol. II; Stehr, F. W., Ed.; Kendall Hunt, 1991; p 144.

26. Colepicolo Neto, P.; Bechara, E. J. H.; Costa, C. Insect Biochem. 1986, 16, 381.

27. Colepicolo Neto, P.; Costa, C.; Bechara, E. J. H. Insect Biochem. 1986, 16, 803.

28. Colepicolo Neto, P.; Bechara, E. J. H., Ferreira, C.; Terra, W. R. Comp. Biochem. Physiol. 1987, 87B, 755 .

29. Redford, K. H. Biotropica 1984, 6, 112.

30. Cilento, G.; Adam, W. Free Radic. Biol. Med. 1995, 19, 103.

31. Timmins, G. S.; Penati, C. A. A.; Bechara, E. J. H.; Swartz, H. M. J. Experim. Biol. 1999, $202,2631$.

32. Timmins, G. S.; Bechara, E. J. H.; Swartz, H. M. J. Exp. Biol. 2000, 203, 2479.

33. Trimmer, B. A.; Aprille, J. R.; Dudzinski, D. M.; Lagace, C. J.; Lewis, S. M.; Michel, T.; Qazi, S.; Zayas, R .M.. Science 2001, 292, 2486.

34. McElroy, W. D.; Seliger, H. H. In Horizons in Biochemistry; Kasha, M.; Pullman, B., Eds. Academic Press: New York, 1962, p 91.

35. Seliger, H. H. Photochem. Photobiol. 1975, 21, 355.

36. Wood, K. W. Photochem. Photobiol. 1995, 62, 662.

37. Colepicolo Neto, P.; Camarero, V. C. C. P.; Eickstein, J.; Hastings, J. W. J. Gen. Microbiol. 1992, $138,1$.

38. Rees, J. F.; de Wergifosse, B.; Noiset, O.; Dubuisson, M.; Janssens, B.; Thompson, E. M. $J$. Exp. Biol. 1998, 201, 1211.

39. Dubuisson, M.; Marchand, C.; Rees, J. F. Luminescence 2004, 19, 339.

40. Dubuisson, M. L. N.; Rees, J. F., Marchand-Brynaert, J. Drug Develop. Ind. Pharm. 2005, $31,827$.

41. Colepicolo Neto, P.; Bechara, E. J. H. Arq. Biol. Tecnol. 1984, 27, 439.

42. Chen, Q.; Haddad, G. G. J. Exp. Biol. 2004, 207, 3125.

43. Torres, M. A.. MSc Dissertation. Chemistry Institute, Sao Paulo University 2003, 53 pp.

44. Barros, M. P.; Bechara, E. J. H. Free Radic. Biol. Med. 1998, 24, 767.

45. Barros, M. P.; Bechara, E. J. H. Insect Biochem. Mol. Biol. 2001, 31, 393.

46. Halliwell, B.; Gutteridge, J. M. C. Free Radicals in Biology and Medicine; 4th Edition; Oxford University Press: 2006.

47. Barros, M. P.; Bechara, E. J. H. Photochem. Photobiol. 71, 2000, 648. 
48. Viviani, V. R.; Bechara, E. J. H. Photochem. Photobiol. 1996, 63, 713.

49. Viviani, V. Cell Mol. Life Sci. 2002, 59, 1833.

50. Timmins, G. S.; Jackson, S. K.; Swartz, H. M. J. Mol. Evol. 2001, 52, 321.

51. Lall, A. B.; Cronin, T. W.; Carvalho, A. A.; Bechara, E. J. H.; Ventura, D. S. F.; Souza, J.; Colepicolo-Neto, P.; Viviani, V. R. J. Insect Physiol. 2000, 41, 1137. 